\title{
Informação e pós-modernidade na fábula do Chapeuzinho Vermelho ${ }^{1}$
}

\author{
Information and postmodernity in the fable of Little Red Riding Hood
}

\author{
Cláudia Ferreira Pinheiro \\ Mestre em Educação pela Univali, SC. \\ Professora responsável pelo laboratório de informática do Grupo Escola Paula Serra, Itajaí, SC. \\ cfpinheiro@terra.com.br
}

\section{Resumo}

Analisa a fábula do filme de animação Deu a louca no Chapeuzinho, com a categoria deleuziana do rizoma, para poder superar a polarização presente na literatura entre obra e recepção. Polarização representada respectivamente pelos trabalhos de Leo Vygotsky e Hans Robert Jauss, autores mais conhecidos nas áreas da Educação e da Literatura. Rizoma é um dos conceitos mais populares de Deleuze e Guattari e refere-se às conexões sempre múltiplas de ideias, processos e coisas; entendemos a fábula como rizoma porque apresenta uma multiplicidade de versões diferentes da tradicional estória do Chapeuzinho Vermelho. Mas, mais que isto, porque a fábula termina com os personagens em novos agenciamentos, deixando-nos ver que muitas outras histórias de Chapeuzinho poderão ser contadas, além dessas que já conhecemos. As categorias da pósmodernidade como marca, informação, diferenças identitárias e intertextualidade são analisadas.

Palavras-chave: Rizoma. Fábula. Pós-modernidade.

\begin{abstract}
The fable of Hoodwinked is analysed with deleuzian category of rhizoma in order to overcome the polarization between work and reception, polarization respectively represented by the works of Leo Vygotsky and Hans Robert Jauss, authors well known in subject fields as Education and Literature. Rhizome is one of the most popular concepts of Gilles Deleuze and Félix Guattari and refers to connections where multiple ideas, processes and things are assemblaged. We understand the fable as rhizome because it shows a multiplicity of different versions of the traditional story of Little Red Riding Hood. But more than that, we call it a rhizome because the story ends with the characters entering in new assemblages, letting us know so many other stories of Little Red Riding Hood that could be told, beyond those we already know. The categories of post-modernity as trade mark, information, identities and intertextuality are analyzed.
\end{abstract}

Keywords: Rhizome. Fable. Post-modernity.

\section{Introdução}

Esta reflexão analisa o filme de animação Deu a louca no Chapeuzinho. A produção cultural de artefatos midiáticos tem sido contemplada nos estudos de mediação, preferencialmente através da análise da obra, tal como ela se apresenta em revistas, filmes ou produção literária, em referenciais teóricos onde a linguagem tem um sentido forte de performatividade.

\footnotetext{
1 Texto apresentado originalmente no $7^{\circ}$ Seminário de Pesquisa em Educação da Região Sul (Anpesul) em 2008 e aqui modificado para publicação final.
}

InCID: R. Ci. Inf. e Doc., Ribeirão Preto, v. 1, n.1, p. 112-124, 2010. 
Já em áreas como a de comunicação ou letras, privilegiam-se os estudos de recepção da obra, já lidando com uma concepção de linguagem menos performática e mais simbólica, onde se fala mais em linguagem como mediação da relação do homem com o mundo.

A cartografia desta polarização obra-recepção está de alguma forma delineada em Mostafa (2006) na força do estruturalismo francês na análise dos produtos midiáticos. Ao estruturalismo francês dos anos 50 e 60 seguem-se os estudos culturais britânicos da década de 70, até porque estes dois movimentos intelectuais privilegiaram, respectivamente, obra e recepção.

O que queremos neste breve desenvolver teórico é apontar formas de superação da polarização obra-receptor. Não sem antes apresentar dois marcos teóricos que consideramos fundantes das duas posições: Vygotsky na defesa da estrutura interna da obra de arte, como núcleo de significância da reação estética (seja a obra uma comédia, uma tragédia, uma pintura, escultura ou poesia) e Jauss na defesa da recepção da obra literária. Vygotsky é um autor mais conhecido na ciência da informação ou na área da educação, enquanto que Jauss é um autor conhecido na área de letras, dada sua reflexão referir-se aos textos literários. Outra consideração importante é que Vygotsky escreve em 1926, inclusive dialogando com o formalismo russo e Jauss está na Europa estruturalista dos anos 60, estruturalismo esse que também mantém certo diálogo com o formalismo russo.

Uma dentre as questões levantadas por ambos os autores é entender a perenidade da obra de arte. Porque certas obras continuam a nos encantar, atravessando os tempos? Vygotsky responde a isso mencionando o próprio Marx no texto da crítica à economia política, dizendo-nos que "[...] no fundo é a mesma questão da complexa influência da superestrutura que Marx levanta" (VYGOTSKY, 2001, p. 22), isto é, deve haver um motivo para que obras do passado ainda continuem a nos encantar no presente, se as relações econômico-sociais do passado e do presente são tão díspares. A resposta de Vygotsky é que nenhuma estética evita a psicologia e, portanto, seria necessário estudar outras variáveis além das sociológicas. O autor apresenta então seu conceito de catarse como algo que pode explicar a perenidade da obra de arte. Não há tanta especificidade na definição vigotiskiana de catarse, além da proposta aristotélica relacionada à potência de agir. A obra de arte provoca uma reação estética chamada catarse, e essa direciona as ações humanas. É interessante que tanto Vygotsky quanto Jauss estão procurando respostas para lacunas não resolvidas nas agendas 
teóricas que consultam. Vygotsky, por exemplo, está fundando uma Psicologia da Arte, em contraposição à Estética filosófica e à Sociologia da arte.

Na área de literatura, Hans Robert Jauss (1979) propõe uma teoria da recepção para preencher a lacuna entre a estética e a história da arte "[...] a estética se concentrava no papel de apresentação da arte, e a história da arte se compreendia como história das obras e dos seus autores [...]" (JAUSS.1979, p. 44). Jauss propõe então uma teoria da recepção, como esclarece Zilberman (1989 p. 33).

Há, em ambos os autores, muita semelhança com relação ao conceito de catarse, apesar de estarem situados em polos distintos da produção cultural, ambos tentando esclarecimentos quanto à historicidade da obra de arte. Para Jauss, o leitor atualiza a percepção do texto literário quando há reconstituição de seu horizonte. Ele reconhece a resposta implícita no texto, resposta esta oriunda de uma pergunta que o leitor adapta ao seu contexto histórico social. Ou seja, o leitor entende que o texto foi escrito para um contexto histórico-social diferente do seu, onde a forma e a estética obedeciam à expectativa vigente da época da produção literária. Compreendendo o horizonte passado, há uma adaptação às expectativas atuais; sendo assim, o texto é re-significado e há uma fusão de horizontes de expectativas. As obras permanecem no tempo se continuam provocando o leitor. Com esta teorização, Jauss explica a historicidade do texto literário.

\section{A Fábula, a Mídia e a Atualização}

As fábulas infantis são um exemplo de perenidade inconteste no quadro das produções culturais. Mas elas só se perenizam ao se atualizarem. Proporemos então o conceito de rizoma de Deleuze \& Guattari (1995) como forma de superação da polarização obra-recepção. Nesta concepção, destacaremos algumas características do rizoma como o da cartografia em oposição ao decalque: o novo mapa da fábula traçado na animação Deu a louca no Chapeuzinho.

Rizoma é um dos conceitos mais populares de Deleuze e Guattari e refere às conexões sempre múltiplas de ideias, processos e coisas; entendemos a fábula como rizoma porque apresenta uma multiplicidade de versões diferentes da tradicional estória do Chapeuzinho Vermelho. Mas, mais que isto, porque a fábula termina com os personagens em novos 
agenciamentos, deixando-nos ver que muitas outras histórias de Chapeuzinho poderão ser contadas, além dessas que já conhecemos.

Já que o rizoma procede "[...] por expansão, conquista, captura, picada". Já que o rizoma é "[...] oposto ao grafismo, ao desenho ou à fotografia, oposto aos decalques"; entenderemos a nova versão como um mapa “[...] desmontável, conectável, reversível, modificável, com múltiplas entradas e saídas, com suas linhas de fuga" (DELEUZE e GUATTARI, 1995 p. 33).

Isto não autoriza uma celebração das adaptações pura e simplesmente, pois há o melhor e o pior no rizoma. Trata-se então de analisar todas as suas linhas, as molares e as moleculares, as linhas duras que estratificam o plano e as linhas de fuga que fazem fluir, expandindo as relações e fazendo-as crescer.

Chapeuzinho Vermelho é um clássico dos contos de fadas da literatura infantil, cujas metamorfoses têm sido estudadas desde a grande transformação sofrida no século XIX quando da versão romântica dos irmãos Grimm. Nesta atualização novecentista, há a interferência dos caçadores para salvar as vítimas do lobo mau. Mas pode-se identificar várias estórias da mesma fábula: Capuchinho Vermelho - Charles Perrault (1697); Chapeuzinho Vermelho - irmãos Grimm (século 19); Chapeuzinho Vermelho de raiva - Mario Prata (1970); Chapeuzinho Amarelo - Chico Buarque (1997); Fita verde no cabelo - Guimarães Rosa (1988).

Não é o caso de visitarmos cada versão já apresentada, mas apenas apontar que, no norte da França, o historiador americano Darnton assinalou 35 diferentes versões diferentes, durante a Idade Média, conforme Cunha (2007). A primeira versão impressa de Perrault de 1697 tem o final trágico em que a avó e a Chapeuzinho Vermelho são devoradas pelo lobo. Na versão dos irmãos Grimm do século XIX, o caçador salva a menina, tira a avó da barriga do lobo e coloca pedras no lugar, versão que se tornou a mais famosa.

É preciso também considerar a pedagogização da cultura como uma linha de estratificação do rizoma-fábula, pois como coloca Giovinazzo Jr. (2004) as modificações atendem os padrões da indústria cultural, no sentido de aligeirar e descontextualizar os conteúdos das histórias infantis, de maneira a facilitar a penetração e assimilação dos contos nas escolas. É inegável que a cultura de massa atua fortemente, principalmente em conteúdos liberados da propriedade intelectual, inundando as escolas e os currículos de estórias infantis

InCID: R. Ci. Inf. e Doc., Ribeirão Preto, v. 1, n.1, p. 112-124, 2010. 
sempre recriadas. Ao apontar modificações em estórias como Pinóquio, A Bela Adormecida, Branca de Neve, Robinson Crusoé e outras, Giovinazzo Jr. conclui, com pertinência, que a lógica da indústria cultural acaba por reduzir essas histórias apenas ao fantástico e ao imaginário, sem qualquer referência às realidades concretas das épocas em que foram escritas e impossibilitando também pensar as realidades concretas vividas pelas crianças dos dias de hoje.

Para atualizar uma fábula em nossa contemporaneidade, lembramos que vivemos em um espaço-tempo mais veloz e abundante em informações, imagens e sons; mudança no espaço e no tempo ocasiona, no mais das vezes, modificações também nas concepções da verdade. Assim, surgem autores para explicar estas modificações em cada uma das suas variáveis, sejam elas econômicas, artísticas ou científicas. Por exemplo, Lyotard (1988) explicitou a mudança na forma de narrar da contemporaneidade, sem o apelo às metanarrativas; Jameson (1996) tratou das produções culturais, defendendo a autenticidade do modernismo; Harvey (1992) mostrou a compressão do espaço-tempo na aceleração do giro do capital. Pélbart (2003) lembra que os autores que discutem explicitamente a pós-modernidade, quase nunca lembram o nome de Deleuze neste debate, mas vêm dele, os conceitos tão largamente utilizados no debate, como diferença, multiplicidade, intensidade, fluxos, virtual.

Consideramos o primeiro platô de Mil Platôs suficiente para introduzir esses conceitos. Trata-se do texto onde os autores lançam o conceito de rizoma como metáfora de pensar o mundo ou como uma imagem do pensamento; iniciam o platô dizendo que um livro não tem objeto nem sujeito e que num livro, como em qualquer coisa, “[...] há linhas de articulação ou segmentaridade, estratos, territorialidades, mas também linhas de fuga, movimentos de desterritorialização e desestratificação". (DELEUZE e GUATTARI, 1995, p. $11)$.

Da mesma maneira, podemos pensar que a fábula possui linhas de articulação ou segmentaridade, mas também perfaz movimentos de desterritorialização. Pois há velocidades e retardamento no escoamento entre as linhas. Deleuze \& Guattari vão chamar esse conjunto de linhas e de velocidades mensuráveis de agenciamento. "Um livro é um tal agenciamento e como tal inatribuível [...] é uma multiplicidade” (DELEUZE e GUATTARI, 1995, p. 12).

Semelhantemente a um novelo de lã, o rizoma é um tal agenciamento. Ao explicar as rupturas a-significantes do rizoma, os autores sugerem o conceito de devir, em oposição à imitação ou à mimese:

InCID: R. Ci. Inf. e Doc., Ribeirão Preto, v. 1, n.1, p. 112-124, 2010. 
[...] o crocodilo não reproduz um tronco de árvore como o camaleão não reproduz as cores de sua vizinhança [...] A Pantera Cor-de-Rosa nada imita, nada reproduz; ela pinta o mundo com a sua cor [...] é o devir-mundo, de forma a tornar-se ela mesma imperceptível (DELEUZE e GUATTARI, 1995, p. 20).

Ainda neste princípio de a-significância, os autores sugerem que devamos "[...] seguir sempre o rizoma por ruptura, alongar, prolongar, revezar a linha de fuga, fazê-la variar, até produzir a linha mais abstrata e a mais tortuosa, com $n$ dimensões, com direções rompidas" (DELEUZE e GUATTARI, 1995, p. 20).

\section{Características da Pós-modernidade em Chapeuzinho}

Além de categorias filosóficas como diferença, multiplicidade, intensidade, fluxos, virtual em Deleuze \& Guattari, outras características da pós-modernidade vieram se somar aos discursos pós-modernos, como a questão da dúvida pós-moderna em Burbules (2000), que justamente se vale do humor para problematizar os paradoxos de nossa época.

Paródias, ironias, deboche, pastiche parecem ser as categorias descritivas do nosso tempo cultural e estariam sendo recomendadas por autores que fazem a crítica à representação e à verdade modernas. Justamente para desestabilizar as verdades e as interpretações de mão única. A ironia, além de apontar o ridículo com atitude de desprezo ou menosprezo, também aponta para o caráter ambíguo do sentido, o que interessa a uma lógica das multiplicidades.

Os procedimentos textuais pós-modernos, utilizando citações a autores, como em qualquer texto científico são transportados para as artes, em romances ou filmes, novelas ou programas de televisão. Assim, a intertextualidade é também mais um lugar para a ironia, pois os intertextos desconcertam os usos comuns da linguagem. Também o pastiche se traduz numa forma de apropriação de um texto, redobrando-lhes os conceitos, entortando-lhes os sentidos, recuperando formas e expressões, mas para dar-lhes novos sentidos, o que mostraria que sempre há traços novos em caminhos já trilhados.

Diferente da cópia fiel a um autor, o pastiche é a possibilidade de escrever um texto com o outro texto, mas misturando códigos que geram uma nova situação. Todos esses processos foram nomeados, às vezes de fragmentação e outras de heterogeneidade; para pensá-los, Deleuze propõe o conceito como devir. Devir pela composição, tanto na natureza quanto na arte. E mesmo na formulação filosófica, “[...] o conceito é questão de articulação,

corte e superposição. É um todo porque totaliza seus componentes, mas é um todo InCID: R. Ci. Inf. e Doc., Ribeirão Preto, v. 1, n.1, p. 112-124, 2010. 
fragmentário" (DELEUZE e GUATTARI, 1995, p. 27). Em vários outros momentos, os autores vão dizer que o conceito é uma heterogênese, isto é, multiplicidade e devir; a migração dos conceitos é uma das vias para sair da transcendência, porque liga os conceitos aos problemas a resolver.

Sinopse da animação: A tranquilidade da vida na floresta é alterada quando um livro de receitas é roubado. Os suspeitos do crime são Chapeuzinho Vermelho (Red), o Lobo Mau, o Lenhador e a Vovó, mas cada um deles conta uma história diferente sobre o ocorrido. Cabe então ao inspetor Nick Pirueta investigar o caso e descobrir a verdade.

Destacaremos a cena do crime como base para o desenrolar da animação e três aspectos da pós-modernidade na análise do filme, a saber: a) a importância da marca e da informação na produção dos doces; b) as diferenças dos personagens com relação à fábula tradicional, na variação das identidades diante dos encontros; c) intertextualidade com relação a outros textos-produtos culturais.

\section{A Marca e a Informação}

Nesta atualização, há na floresta um ladrão de receitas de guloseimas chamado de "o ladrão das guloseimas”. Ele rouba as receitas e, por isso, as confeitarias da floresta fecham numa demonstração do valor da informação em relação à experiência do ofício; a informação é mais valorizada do que o fazer, tipificando uma sociedade de serviços. Sem o livro de receitas não há a produção de guloseimas, desprezando assim o saber-fazer da tradição de uma confeitaria. Até a tradicional marca de doces Puckett - guloseimas escandalosamente deliciosas (slogan da marca Puckett) - foi um resultado de acúmulos de informações gastronômicas e não resultado de experiências vivenciadas entre farinhas e ovos dos membros da família.

Como vemos na fala da avó para a neta:

- Cada receita aqui veio da família Puckett. Geração após geração... Ali está a Sylvia Puckett no Polo Norte. Lá ela encontrou o melhor chocolate... Aquela é Emma Puckett, que cruzava o Atlântico com queijadinhas. Os Pucketts vêm coletando e refinando receitas do mundo todo, dando-lhe o toque especial dos Pucketts. Vê, Chapeuzinho, ao vestir o capuz, você carrega uma linda tradição.

InCID: R. Ci. Inf. e Doc., Ribeirão Preto, v. 1, n.1, p. 112-124, 2010. 
Nesta última fala - "ao vestir o capuz, você carrega uma linda tradição" - podemos perceber a ironia pós-moderna onde a indústria capitalista faz da tradição, uma mercadoria, ao usar um signo da fábula tradicional como slogan de uma marca empresarial capitalista. Harvey (1992) pondera a necessidade de fixação das marcas na sociedade pós-moderna, sociedade que, embora lide com a efemeridade e volatilidade de tudo, ainda necessita fixar as marcas como imagem de respeitabilidade e estabilidade. Assim, o capuz vermelho é também uma marca a ser preservada no dinamismo na sociedade pós-moderna.

Nos modos desta contação da história de vida dos antepassados da família Puckett, é possível perceber a linguagem de um discurso indireto, próprio ao que Deleuze e Guattari chamam de agenciamento coletivo de enunciação. "O discurso indireto é a presença de um enunciado relatado em um enunciado relator, a presença da palavra de ordem na palavra" (DELEUZE e GUATTARI, 1995a, p. 23).

O que os autores explicitam é que a consciência de si é construída a partir de transformações incorpóreas das palavras de ordem presentes em um discurso indireto. "Uma potência de esquecimento que faz com que nos sintamos inocentes diante das palavras de ordem que seguimos e, depois abandonamos, para acolher outras em seu lugar" (DELEUZE e GUATTARI, 1995a, p. 24). Assim, Red se lembra dos ensinamentos que recebera sobre a tradição familiar, ensinamentos que agora terá que substituir por outros. Um jogo de cores, imagens e música agenciam a passagem e a transformação de Red em Blue.

Ainda na explicação da avó para a neta, podemos observar outra ironia pós-moderna:

- Desde que se descobriu que bichos adoram guloseima, é muito importante garantir que o mundo continue doce.

Transformar animais em consumidores de doce, numa sociedade capitalista, ironiza duplamente a atualização desta fábula com o uso de animais para perpetuar suas características, que neste caso transformam-se em consumidores. E a docilidade do mundo transmitida pelas fábulas tradicionais em finais felizes e bons costumes morais.

\section{A Diferenciação dos Personagens}

É curioso observar que a cena inicial (O lobo disfarçado de vovozinha e o Chapeuzinho e vovó sendo salvas por heroico lenhador), base desta animação, é também o InCID: R. Ci. Inf. e Doc., Ribeirão Preto, v. 1, n.1, p. 112-124, 2010. 
início de uma nova fabulação. É neste cenário que acontecem os diversos atravessamentos dos personagens relatados em versões. Temos então o início e o fim de uma versão no mesmo cenário, como as voltas de um bumerangue. Em cada volta há uma mudança de perspectivas, de verdades e de identidades, demonstrando a multiplicidade das verdades diante dos agenciamentos em jogo.

O lobo que aterroriza Red na floresta escura é o tradicionalmente "lobo mau" na versão de Red. Mas, na réplica do lobo, o seu gesto ameaçador foi resultado de uma beliscada acidental em sua cauda, no momento em que ele fazia uma investigação jornalística, como repórter.

A vovozinha frágil, inofensiva e boazinha na idealização de Red, mente e pratica esportes radicais no alto das montanhas enquanto sua neta entrega doces na monotonia da floresta. A avó não estava amarrada no armário e sim enrolada em seu paraquedas, após descida atrapalhada das montanhas (participava das Olimpíadas de inverno; ao esquiar nas montanhas, foi sabotada e jogada do penhasco; na queda, ela entra pela chaminé de paraquedas, se enrosca nas cordas do paraquedas e fica presa no armário).

O lenhador heroico e salvador da estória tradicional é um ator incorporando um lenhador como personagem para anúncio televisivo, que acidentalmente cai dentro da casa da vovó.

O coelhinho felpudo e fofinho, símbolo da inocência e docilidade é um bandido mal, muito mal, como ele mesmo se denomina.

O sapo-investigador (Nick Pirueta) porta a ambiguidade de um anfíbio que transita pela água e pelo ar, assim como transita entre a dança e a investigação.

A Red, uma das personagens centrais da fábula, está em transição da fábula tradicional para a presente atualização. Assim como a Red quer mudar e ver o mundo, o coelhinho felpudo também quer mudar e ser um coelhinho mal, quebrando a tradição da fábula onde os animais perpetuam suas características. Percebemos as transformações de Red em dois momentos que se apoiam nos temas musicais. No primeiro momento, Red, em sua rotina de entrega dos doces Puckett, pedala em sua bicicleta pela floresta, cena que demonstra a insatisfação da menina traduzida na música de fundo: "Vou lhe contar uma estória/ De uma menininha que saiu de bicicleta/ Ela nunca era indelicada nem maldosa/ Tirem-me da floresta, quero ganhar o mundo/ Mundo, eu quero você".

InCID: R. Ci. Inf. e Doc., Ribeirão Preto, v. 1, n.1, p. 112-124, 2010. 
No segundo momento, Red descobre a verdadeira identidade de sua (pós-moderna) avó:

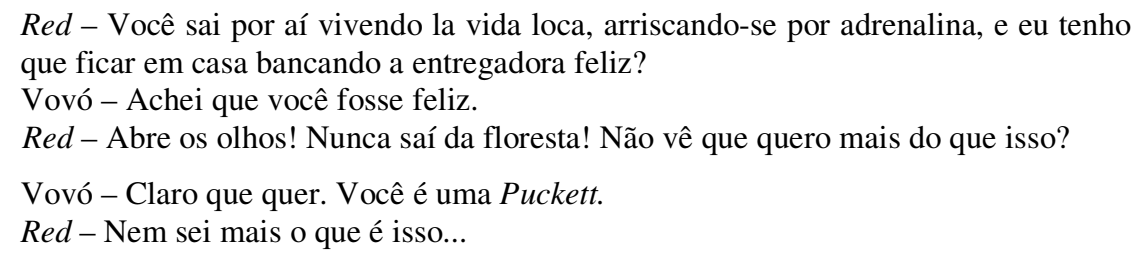

Red tira o capuz vermelho, que a ligaria à tradição familiar, e se afasta para pensar. Sem capuz e triste, vagueia pela floresta. O capuz é um signo de identificação da menina da fábula, mas é também uma variável em um agenciamento. Sem o capuz, a tela fica azul e a canção Red is Blue preenche todos os espaços. As lembranças da menina neste momento de recordação das estórias (mal) contadas pela avó são trazidas à memória em cenas vermelhas. "O sistema linha (ou bloco) do devir opõe-se ao sistema ponto da memória" (DELEUZE e GUATTARI, 1997, p. 92). A música Red is blue diz: "Tudo está mudando/ E você se sente a garota mais sozinha do mundo/ E não sabe o que fazer/ Mas vermelho ficou azul/ Dentro do seu coração você colocou tantas coisas/ Todos os momentos e tudo o que ela disse/ E agora Red está triste”.

Independentemente das versões apresentadas pelos quatro personagens envolvidos (Chapeuzinho, Lobo, Lenhador e Vovó), as diferentes identidades dos personagens são resultado dos agenciamentos em questão. "Os agenciamentos não cessam de variar, de ser eles mesmos submetidos a transformações" (DELEUZE e GUATTARI, 1995a, p. 20). Por exemplo, quando Chapeuzinho encontra um lobo querendo roubar sua cesta de doces numa floresta escura, onde o lobo dá um grito aterrorizador, sua interpretação assim agenciada só poderia ser a de um "lobo mau". O lobo, por sua vez, ao procurar o ladrão da guloseima identifica na menina, que circula por toda a floresta, uma suspeita que teria como principal motivo, ao roubar as outras receitas, manter a hegemonia da marca Puckett. Evidencia-se assim a multiplicidade de situações nesses e em outros personagens da animação.

\section{Intertextualidade}

A animação usa fartamente os recursos discursivos de um texto dentro do outro; o filme começa com a casa da vovó cercada como numa cena de crime em filmes policiais, com InCID: R. Ci. Inf. e Doc., Ribeirão Preto, v. 1, n.1, p. 112-124, 2010. 
faixas amarelas de "não ultrapasse", e onde as falas são permeadas por jargões típicos do deboche pós-moderno. A pós-modernidade se contrapõe ao moderno por privilegiar, nas artes, o pastiche, a colagem, o kitsch, a ironia, a sátira. A crítica pós-moderna é cheia de ironia e não é dirigida à busca da verdade, até porque é a concepção mesma de verdade que está em cheque. É uma crítica, portanto, que ao denunciar incorpora parte das denúncias, numa reciclagem criadora de estilos. "No pós-modernismo, dissolvem-se também as rígidas distinções entre diferentes gêneros: entre filosofia e literatura, entre ficção e documentário, entre textos literários e textos argumentativos" (SILVA, 2002, p. 114).

Assim, numa das falas iniciais do policial, quando ele afirma já ter desvendado o caso, nota-se seu estilo debochado: "O Lenha sacodiu o machado e o Lobão queria dar cabo da pequerrucha; Capinha rosa fazia entregas clandestinas para o Guloseima; aí o Lobão tenta comer a duas, mas o Lenha aqui dá uma de justiceiro".

Em meio à movimentação dos policiais, vemos a chegada de Nick Pirueta, o refinado sapo-inspector, destilando ironia ao desprezar a capacidade profissional dos policiais, como nos filmes americanos, em que o agente do FBI inicia os trabalhos desmoralizando os policiais locais: temos 4 suspeitos, ou seja, 4 versões.

Outro momento bem característico de intertextualidade vemos na cena em que Chapeuzinho luta com o coelhinho mau, no formato da luta marcial, semelhante ao filme Matrix. Temos cenas em slow motion, congelamentos e gestos semelhantes às lutas do personagem Neo contra o agente Smith no filme Matrix.

\section{Considerações Finais}

As versões das fábulas podem e devem ser consideradas como novos produtos culturais em que a noção do devir serve melhor aos propósitos de uma atualização e pode ser trabalhada no par virtual-atual. Entre um estado e outro, ocorre a produção de novos afectos e perceptos.

A literatura é devir, conforme Deleuze, e devir não é nunca imitação, idealização, metáfora, comparação, mas uma dupla captura. Assim, são releituras da tradição, não imitação. Releituras que incorporam o pastiche, o deboche, a ironia em suas linhas de segmentarização e ruptura. Em cenas iniciais do filme, há uma voz off enunciando: "Se InCID: R. Ci. Inf. e Doc., Ribeirão Preto, v. 1, n.1, p. 112-124, 2010. 
quiseres saber as verdades de um livro, temos que virar as páginas"; numa alusão às novas edições sempre disponíveis de um livro, ou metaforicamente, à repaginação no sentido de uma atualização. “[...] Um livro não tem objeto nem sujeito; é feito de matérias diferentemente formadas, de datas e velocidades muito diferentes. Desde que se atribui um livro a um sujeito, negligencia-se este trabalho das matérias e a exterioridade de suas correlações" (DELEUZE e GUATTARI, 1995, p. 11).

Na cena final do filme, o sapo-investigador se diz funcionário de uma agência secreta, Agência Felizes para Sempre, agência que garante histórias com finais felizes. Ao convidar as personagens da fábula para trabalharem nesta agência, o sapo ironiza: há muitas estórias por aí que precisam de finais felizes. Red então coloca seu capuz vermelho por sobre a cabeça e responde: eu sempre gostei de finais felizes. Soa como mais um momento de ironia, pois esta atualização questiona justamente os finais felizes, na medida em que as várias versões marcam a verdade como agenciamento e não origem ou essência do mundo. “[...] Um livro tampouco tem objeto. Considerado como agenciamento, ele está somente em conexão com outros agenciamentos." (DELEUZE e GUATTARI, 1995, p. 12).

O convite aos personagens para trabalhar na Agência marca o princípio de multiplicidade do rizoma-fábula, pois nenhum dos personagens permanece o mesmo, após a enunciação das versões. Eles integrarão outras fábulas e outras estórias, a partir de agora, na nova agência. "Uma multiplicidade não tem sujeito nem objeto, mas somente determinações, grandezas, dimensões que não podem crescer sem que mude de natureza" (DELEUZE e GUATTARI, 1995, p. 16).

Entendemos assim, o processo de atualização-fabular como um agenciamento, definido como "[...] este crescimento das dimensões numa multiplicidade que muda necessariamente de natureza à medida que ela aumenta suas conexões". (DELEUZE e GUATTARI, 1995, p. 17). Red is Blue, por que não?

\section{Referências}

BURBULES, N.C. AS dúvidas pós-modernas e a filosofia da educação. In: GHIRALDELLI, P. (Org.). O que é filosofia da educação? Rio de Janeiro: DP\&A, 2000.

CUNHA, R. Deu a louca na narrativa infantil? Ciência e Cultura, São Paulo, v.59, n.1, jan./mar. 2007. Disponível em : $<$ http://cienciaecultura.bvs.br/scielo.php?script=sci_arttext\&pid=S0009 $67252007000100028 \& \operatorname{lng}=$ pt\&nrm=iso $>$. Acesso em: 24 out. 2007. 
DELEUZE, G.; GUATTARI, F. Mil Platôs. Capitalismo e Esquizofrenia. Rio de Janeiro: Editora 34, 1995. v.1

1995a. v.2

. Mil Platôs. Capitalismo e Esquizofrenia. Rio de Janeiro: Editora 34, 1997. v.4

. Mil Platôs. Capitalismo e Esquizofrenia. Rio de Janeiro: Editora 34,

DEU a Louca na Chapeuzinho. Direção: Cory Edwards, Barueri:Europa Filmes, 2007.

GIOVINAZZO JR., C. A. Cultura, educação e Indústria Cultural: a pedagogização das práticas culturais e as transformações da literatura infantil. In: COLÓQUIO

INTERNACIONAL TEORIA CRÍTICA E EDUCAÇÃO, 2004, Araraquara. Anais... Araraquara: UNIMED, 2004. p 13-17.

HARVEY, D. Condição pós-moderna. São Paulo: Loyola, 1992.

JAMESON, F. Pós-modernismo: a lógica cultural do capitalismo tardio. São Paulo: Ática, 1996.

JAUSS, H. R. A estética da recepção: colocações gerais. In: LIMA, L. C. (Coord.). A Literatura e o leitor: textos de estética da recepção. Rio de Janeiro: Paz e Terra, 1979.

LYOTARD, J-F. O pós-moderno. Rio de Janeiro: Ed. José Olympio, 1988.

MOSTAFA, S. P. A força do estruturalismo francês na análise dos produtos midiáticos. Educação Unisinos, São Leopoldo, v.10, n.3, p. 237-242, set./dez. 2006.

PELBART, P. P. Vida capital: ensaios de biopolítica. São Paulo: Iluminuras, 2003.

SILVA, T. T. Documentos de identidade: uma introdução às teorias do currículo. Belo Horizonte: Autêntica, 2002.

VYGOTSKY, L. Psicologia da arte. São Paulo: Martins Fontes, 2001.

ZILBERMAN, R. Estética da recepção e história da literatura. São Paulo: Ática, 1989. 